\title{
TRABALHO INFANTIL NO MUNICÍPIO DE ITAPETINGA-BA: \\ ações e estratégias para erradicação
}

Clébio Moreira Lemos*

Reginaldo Santos Pereira**

Resumo: Este artigo é resultado de uma pesquisa qualitativa realizada no município de Itapetinga (BA), cujo objetivo foi conhecer o panorama de dados sobre a exploração do trabalho infantil e analisar as medidas preventivas e protetivas realizadas pelo Conselho Tutelar, Programa de Erradicação do Trabalho Infantil (PETI) e Programa de Educação Contra a Exploração do Trabalho da Criança e do Adolescente (PETECA). A investigação traz um recorte das entrevistas realizadas com os Conselheiros Tutelares e os coordenadores dos Programas PETI e PETECA.

Palavras-chave: Direitos. Exploração. Trabalho infantil

\section{CHILD LABOR IN ITAPETINGA: actions and strategies for eradication}

\begin{abstract}
This article is the result of a qualitative research realized in Itapetinga, Bahia, Brazil, whose objective was understanding the data viewpoint on child labor exploitation and analyzing the preventive and protective measures performed by the Conselho Tutelar (Tutelary Council), Programa de Erradicação do Trabalho Infantil (Program for the Elimination of Child Labor, PETI) and Programa de Educação Contra a Exploração do Trabalho da Criança e do Adolescente (Education Program Against the Exploitation of Child and Adolescent Labor, PETECA). The research brings a part of the interviews with the Tutelary Counselors and the Program Coordinators of the PETI and the PETECA.
\end{abstract}

Keywords: Rights. Exploitation. Child Labor.

\footnotetext{
* Graduado em Pedagogia (UESB), Pós-Graduação Lato Sensu em Políticas Públicas e Gestão Educacional (UESB), Conselheiro Tutelar de Itapetinga-Ba. E-mail: clebiolemos366@gmail.com

** Doutor em Educação (UFSCar), Professor do Programa de Pós-Graduação em Educação (PPGED-UESB). E-mail: reginaldouesb@gmail.com
} 
Introdução

O trabalho infantil é um grande problema social que atinge diversos países, em especial os subdesenvolvidos, onde crianças e adolescentes, muitas vezes por causa da pobreza em que vivem com suas famílias, são impulsionados a começarem a trabalhar precocemente, deixando de usufruir de etapas importantes de sua vida.

No Brasil, mesmo com a ampliação do sistema protetivo a partir da implementação de leis que garantem os direitos humanos, como por exemplo, à Consolidação das Leis Trabalhistas de 1943 (CLT), a Constituição Federal de 1988 (CF) e Estatuto da Criança e do Adolescente 1990 (ECA), milhares de crianças e adolescentes estão trabalhando precocemente nos mais variados ambientes, como: lavouras, fábricas, casas de famílias, feiras livres, matadouros, clubes e bares; em regime de exploração, quase escravidão, já que além de executar atividades proibidas pela legislação, recebem como pagamento um valor pífio, considerado pelo empregador como uma "ajuda" de custo para a vítima e a família, o que se configura como custo benefício para o explorador, uma vez que não são garantidos os direitos trabalhistas.

A nossa intenção de pesquisa essa temática, tem origem a partir do trabalho exercido como Conselheiro Tutelar, no município de Itapetinga - BA, desde o ano de 2010. Nessa função tivemos a oportunidade de conhecer a realidade que vivem muitas crianças e adolescentes e o quanto essa problemática afeta o processo de escolarização (frequência, rendimento, motivação, desenvolvimento cognitivo, físico, emocional etc.). No decorrer desses anos, foram atendidos casos em que crianças eram impulsionadas pelos pais e/ou responsáveis a irem para as ruas vender produtos de limpeza, trabalhar nas feiras livres, oficinas mecânicas, casas de famílias, venda de picolé nas ruas, tomar conta de veículos no centro comercial, mendigar, entre outros.

Em todos os casos atendidos, as famílias foram convocadas a prestar esclarecimentos. Desses casos, em torno de $60 \%$ declararam que é melhor as crianças estarem trabalhando do que roubando ou traficando. Os outros 40\% relataram que necessitavam do dinheiro para complementar a renda familiar. Todas as vítimas do trabalho infantil que foram convocadas para serem ouvidas na sede do Conselho Tutelar disseram ter dificuldade em absorver os conteúdos ministrados em sala de aula, pois se sentiam cansadas e não conseguiam se concentrar, outras vítimas disseram que já chegaram a dormir, enquanto o professor explicava o assunto.

Percebeu-se na fala de alguns responsáveis que foram convocados a ir até a sede do CT, que além do problema da falta de recursos financeiros, existe uma questão cultural que associa o trabalho à conduta da criança e do adolescente, pois para eles é através da inserção prematura do sujeito no mundo trabalhista que seu caráter moral será moldado. No entanto, começar a trabalhar precocemente faz com que esses sujeitos ultrapassem importantes etapas de sua vida, correndo o risco de perder a oportunidade de no 
tempo certo se qualificar e entrar para o mercado de trabalho. As falas das crianças confirmam o que aponta o Relatório de Desenvolvimento (2012), do Programa das Nações Unidas para o Desenvolvimento (PNUD), onde diz que, no Brasil, um a cada quatro alunos que inicia o ensino fundamental abandona a escola antes de completar a última série. $\mathrm{O}$ trabalho precoce de crianças e adolescentes têm sido um dos fatores que contribui significativamente para defasagem idade/série e a evasão escolar. Algumas dessas crianças e adolescentes terão seu futuro comprometido, pois abandonarão os estudos, não obterão uma boa formação, e serão prejudicados na sua vida social e trabalhista.

Diante desta realidade, este artigo traz o resultado de uma pesquisa qualitativa realizada no município de Itapetinga-BA, situado na Região do Sudoeste Baiano, com uma população estimada em 75. 470 mil habitantes (IBGE, 2018). O lócus foi o Conselho Tutelar, Secretaria de Desenvolvimento Social, através do Programa de Erradicação do Trabalho Infantil (PETI) e a Secretaria Municipal de Educação, por meio do Programa de Educação Contra a Exploração do Trabalho da Criança e do Adolescente (PETECA). Entretanto, este artigo traz um recorte das entrevistas realizadas com os Conselheiros Tutelares, o coordenador do Programa PETI e o coordenador do Programa PETECA, denominado, em âmbito municipal, de Programa MOLECADA, vinculado a Secretaria Municipal de Educação.

O estudo intenciona trazer ao debate e reflexão do papel do poder público, da comunidade local, das escolas, das universidades e outras instituições a promoverem ações voltadas para a erradicação do trabalho infantil e a efetiva garantia do direito ao acesso e permanência das crianças e adolescentes à educação.

\section{O Conselho Tutelar: diálogos com os Conselheiros}

O Conselho Tutelar (CT) de Itapetinga foi legalmente instituído no dia 20 de maio de 1992, através da Lei n 552/92. Contudo, somente no dia 01 de junho de 1999, a estruturação do órgão veio a ser consolidada. Os agentes tutelares trabalham 40 (quarenta) horas semanais, com dedicação exclusiva, buscando garantir que os Direitos Humanos das Crianças e Adolescentes sejam assegurados com absoluta prioridade pela família, comunidade, sociedade em geral e pelo poder publico (Artigo $4^{\circ}$, Lei 8069/90).

O CT tem como missão zelar pelo cumprimento dos direitos das crianças e adolescentes (Artigo 131, Lei 8.069/90) e as suas atribuições são definidas pelos artigos 95 e 136, Lei 8.069/90 do Estatuto da Criança e Adolescente (ECA). É composto por 5 (cinco) membros, escolhidos por votação direta, possui mandato de 4 (quatro) anos, sendo que a Lei limita em apenas uma recondução, mediante um novo processo de escolha (Artigo 132, Lei 8.069/90, modificado pela Lei 12.696/12).

Nas entrevistas realizadas junto aos Conselheiros, para buscar compreender o fenômeno estudado nesta pesquisa, foram utilizadas as letras "X, Y, Z e W" para identificar os seus respectivos 
discursos, a fim de preservar a sua identidade e não ferir a ética da pesquisa científica. Coletamos dados sobre a forma de atuação, estratégias de fiscalização, formação dos membros na identificação dos casos de trabalho infantil, procedimentos adotados pelo órgão, os encaminhamentos, acompanhamento das crianças e adolescentes, suas opiniões sobre a proibição do trabalho infantil a menores de 14 anos, avaliação da relação Estatuto da Criança e Adolescente com a comunidade e, por fim, a autonomia do CT para exercer o seu papel fiscalizador.

No que se refere à forma de atuação do CT, identificamos nas entrevistas que o Órgão deve atuar dentro da comunidade de forma preventiva, em cumprimento ao artigo 70 do ECA, que diz: "É dever de todos prevenir a ocorrência de ameaça ou violação dos direitos da criança e do adolescente", o que não impede a comunidade local, que está atenta aos problemas a sua volta, notificar casos de violação de direitos infanto-juvenis, devendo o CT agir no intuito de evitar que os direitos referentes à criança e o adolescente sejam violados. Para tanto,

Ao Conselho Tutelar são conferidas várias atribuições, que, na prática, resultariam em faculdade de aplicar medidas em relação às crianças e jovens, aos pais ou responsáveis, às entidades de atendimento, em relação ao Poder Executivo, à autoridade judiciária e ao Ministério Público, em relação às suas próprias decisões (LIBERATI; CYRINO, 1993, p. 143).

As atribuições do Conselho Tutelar estão descritas no artigo 136, da Lei 8.069/90. O CT deverá promover a execução das suas decisões, podendo, para tanto, requisitar serviços públicos nas áreas de saúde, educação, serviço social, previdência, trabalho e segurança, e ainda, representar junto à autoridade judiciária nos casos de descumprimento injustificado de suas deliberações, conforme garante o Art. 136, Inciso III.

Em relação a esta questão, em sua fala, o Conselheiro X relatou que:

\begin{abstract}
Na maioria dos atendimentos somos provocados pela sociedade. E como a demanda de atendimentos a esses casos é grande, não nos resta muito tempo para trabalho preventivo. No entanto, realizamos programas preventivos como: palestras em escolas, participação em eventos, fiscalização de órgãos relacionados à proteção de crianças e adolescentes, fiscalização de evasão escolar e acompanhamento das famílias atendidas (Entrevista, fevereiro 2018).
\end{abstract}

Existe uma dualidade na fala do Conselheiro X, já que no primeiro momento, ele diz que na maioria das vezes o CT é provocado pela comunidade, tendo em vista, a quantidade de casos atendidos e, por esse motivo não resta muito tempo para a realização de trabalho preventivo, no entanto, na mesma fala ele afirma que o Órgão realiza programas preventivos. O CT deve antecipar-se ao problema, levando à comunidade as informações em relação ao Estatuto da Criança e Adolescente (ECA), bem como, referente a direitos consagrados nessa Lei. Para isso, é necessário que o CT tenha uma boa relação com os outros Órgãos que compõem o Sistema de Garantia de Direitos (SGD), assim, poderá por em movimento programas e autoridades públicas responsáveis por atender as vítimas que tiveram seus 
direitos ameaçados ou violados.

O trabalho infantil é uma violação de direitos infanto-juvenis, cabendo aos Órgãos que compõem o Sistema de Garantia de Direitos (SGD) ficarem atentos, a fim de verificar a ocorrência desse tipo de situação e buscar meios para erradicá-lo. O CT tem como missão zelar pelo cumprimento dos direitos da criança e do adolescente, portanto, deve fiscalizar se o município está desenvolvendo programas e/ou atividades que visem eliminar a ocorrência desse fenômeno.

Os Conselheiros Tutelares entrevistados ao falarem sobre a fiscalização do trabalho infantil, por parte do CT, relataram que, na maioria das vezes, são provocados pela comunidade, no qual recebem denúncias anônimas ou encaminhamentos da Justiça do Trabalho, dando conta de crianças e adolescentes executando ilegalmente algumas atividades trabalhistas. O Conselheiro Y, falando sobre a existência de mecanismo de fiscalização ao trabalho infantil no CT e sobre como ocorre essa fiscalização, contribuiu com a seguinte afirmação: “[...] Na maioria das vezes quando recebemos denúncias ou a depender do caso, quando vemos adolescentes trabalhando em locais públicos”. Por outro lado, o Conselheiro X fala sobre o trabalho de fiscalização feito pelo órgão, sobretudo na Central de Abastecimento (local que ocorre a feira livre), bem como as medidas aplicadas.

[...] Realizamos fiscalização in loco em pontos onde o trabalho infantil é frequente. A mais recente ação foi realizada na Central de Abastecimento da cidade, onde foi constatada a presença de trabalho infantil e tomamos as devidas providências para acompanhamento dos envolvidos como verificar a matrícula, a assiduidade escolar e violação de outros direitos (Entrevista, fevereiro 2018).

A partir do momento que é constatada a veracidade da denúncia de trabalho infantil, é de suma importância que a rede de atendimento a criança e adolescente, comece a atuar para cessar a violação. A rede de atendimento precisa estar coesa, pois, de forma coletiva, conseguirá enfrentar o problema, buscando soluções e articulando medidas que irão construir políticas públicas de atendimento eficazes. Alberto (2002) chama atenção para a ineficácia ou inadequação das políticas sociais estatais. Nessa perspectiva, os fatores que contribuem para a existência do trabalho precoce na sociedade atual são agravados pela ausência do Estado em não assegurar a garantia dos direitos desses sujeitos em processo de desenvolvimento, mediante a oferta de ações mais efetivas, como a criação de programas sócioeducativos, o funcionamento permanente de creches e de instituições escolares.

É preciso que as pessoas que fazem parte da rede de atendimento à criança e adolescente, recebam formação para identificação de casos de trabalho infantil. Na entrevista foi indagado aos Conselheiros, sobre a formação dos mesmos, na identificação dos casos de trabalho infantil. O Conselheiro W afirmou não receber nenhuma formação: “[...] Atuamos com a experiência do dia a dia e quando a população faz as denúncias" (Entrevista com o Conselheiro W, fevereiro 2018). Verificamos que houve divergência entre a fala do Conselheiro W e o Conselheiro X, pois este último afirmou ter conhecimento de curso de formação, 
[...] Houve um curso de formação para identificação do trabalho infantil dedicado aos Conselheiros, realizado pelo Ministério Público. No entanto, o curso era online e não tive meios de participar no momento (Entrevista, fevereiro 2018).

O curso de formação que o Conselheiro X relata, trata-se de um curso online, ofertado pelo Ministério Público do Trabalho, no mês de outubro de 2017, destinado aos Conselheiros Tutelares de todo país. Embora os Conselheiros Tutelares não tenham falado sobre outros Órgãos que tenham proporcionado cursos para identificação de trabalho infantil, a fim de qualificar os profissionais que trabalham no Sistema de Garantia de Direito da Criança e Adolescente (SGDCA), temos conhecimento de cursos online de capacitação e vídeos conferências anuais que acontecem nos auditórios de videoconferência da rede de educação do Estado da Bahia, desenvolvidos pelo Fórum Estadual de Erradicação do Trabalho Infantis e Proteção ao Adolescente Trabalhador da Bahia (FETIPA).

Percebe-se que as instituições que estão voltadas a buscar soluções para erradicar o trabalho infantil, tem se preocupado em formar sujeitos críticos que possam contribuir para mudar a realidade de milhares de vítimas. Destarte, é preciso que as pessoas que militam na defesa e garantia de direitos humanos da criança e adolescente, tenham a compreensão da necessidade de ter uma formação qualificada, que lhe ajudará a tomar decisões importantes no momento em que se deparar com as mais variadas formas de violações.

$\mathrm{Na}$ coleta de dados dos documentos de atendimentos do CT de Itapetinga, tem descrito todo o processo de atendimento aos casos estudados. Observa-se que quando uma denúncia é encaminhada para o Órgão, os Conselheiros devem verificar a veracidade dos fatos, se comprovado, existem algumas medidas que poderão ser adotadas para tirar a criança e ou adolescente daquele contexto. O Conselheiro $\mathrm{Z}$ ao falar sobre esse assunto, disse que ao receber a demanda, o CT deve "Averiguar a situação e notificar o dono do estabelecimento e os responsáveis". O CT não deve atuar de maneira solta, isolada, sem planejamento com outros Órgãos de defesa, promoção e controle, é de fundamental importância que, nesse caso, exista uma ação planejada com a rede de proteção. A mera realização de intervenções destinadas a coibir a exploração do trabalho infantil, pelo Conselho Tutelar, não trará efeitos positivos, pelo contrário, faz com que a população, encontre motivos para questionar as ações do Órgão.

O Conselheiro X traça um panorama diferente, mas que não está de acordo com as análises que fizemos dos relatórios estudados.

\begin{abstract}
Abertura da ocorrência, notificação da família envolvida, orientação, advertência e aconselhamento, encaminhamento para a Proteção Social Básica e Especial - CREAS, CRAS, PETI, Bolsa Família, verificação da situação escolar, investigação e fiscalização para comprovar a situação de trabalho infantil (Entrevista, fevereiro 2018).
\end{abstract}

Observa-se que os dados analisados nos relatórios de atendimentos do CT de Itapetinga constam, em sua maioria, que os encaminhamentos foram quase todos direcionados ao Centro de Referência Especializado de Assistência Social (CREAS), não tendo nenhuma informação de encaminhamentos para 
o Centro de Referência de Assistência Social (CRAS), Programa de Erradicação do Trabalho Infantil (PETI) e Programa Bolsa Família. Esses programas sociais fazem parte do Sistema Único de Assistência Social e, é integrado a Secretaria Municipal de Desenvolvimento Social de Itapetinga-Bahia. Diante do exposto, compreende-se que é de extrema urgência que os membros do Conselho Tutelar recebam formação continuada, como determina o artigo $4^{\circ}$ da resolução 170 do CONANDA (2014),

A Lei Orçamentária Municipal ou do Distrito Federal deverá estabelecer, preferencialmente, dotação específica para implantação, manutenção, funcionamento dos Conselhos Tutelares, bem como para o processo de escolha dos conselheiros tutelares, custeio com remuneração, formação continuada e execução de suas atividades.

A doutrina da proteção integral estabelecida no Art. $1^{\circ}$ do ECA, deu a criança e adolescente a condição de serem reconhecidos como sujeitos de direitos. Nos casos de violações desses direitos, é dever de todos se mobilizarem para restabelecê-los. Ao falarmos de trabalho infantil, não se pode dar por encerrado o caso, pelo simples fato do sujeito ter sido retirado do local onde ele executava atividade trabalhista. A rede de proteção tem que funcionar de forma efetiva, com o estudo sobre as condições da família, a situação escolar da criança ou adolescente, as atividades executadas, os encaminhamentos a serem feitos, as visitas e outros.

Ao serem inquiridos sobre o acompanhamento das crianças e adolescentes que foram retiradas da situação de trabalho infantil, obtivemos dos Conselheiros Tutelares as seguintes respostas: Conselheiro $\mathrm{X}$ : “O acompanhamento é realizado através de relatórios circunstanciados solicitados aos Órgãos aos quais foram encaminhados"; segundo o Conselheiro Y, "o Conselho faz visitas no intuito de fiscalizar se a criança e a família estão tendo os serviços oferecidos"; já o Conselheiro Z informou serem feitas visitas "para ver se a família está sendo acompanhada" e, por fim, o Conselheiro W relatou que as visitas são realizadas "porque às vezes os genitores pensam que os Conselheiros Tutelares não sabem que os filhos voltaram".

Nota-se pelas falas dos membros do Conselho Tutelar, a falta de organização quanto aos procedimentos em relação ao atendimento a criança, adolescente e suas respectivas famílias. $O$ acompanhamento dos casos não pode ser feito de qualquer jeito, pois se assim o for, as vítimas irão continuar sendo exploradas e o ciclo de violações permanecerá existindo na vida desses sujeitos.

O trabalho infantil é ilegal e tem como suporte jurídico o artigo 403, da Lei no 10.097/2000, que proíbe qualquer trabalho a menores de dezesseis anos, salvo na condição de aprendiz, a partir dos quatorze anos. Em seu parágrafo único, está estabelecido que o adolescente aprendiz não poderá executar atividades em locais que prejudiquem sua formação, desenvolvimento físico e psicológico, moral e social, bem como, em horários e locais que o impeça de frequentar a escola. A análise dos dados primários revela que, embora os Conselheiros Tutelares atuem em um órgão, que em tese, defende o cumprimento dos direitos da criança e adolescente, observa-se mediante as falas dos entrevistados, a dificuldade de reconhecer os direitos fundamentais desses sujeitos, conforme o que preconiza o Artigo 15 da Lei 
8.069/901. Ao se posicionar em relação ao adolescente trabalhador aprendiz, o Conselheiro X se mostra a favor e apresentou o seguinte relato:

[...] acredito que lugar de criança é na escola. A educação é o único caminho que pode amenizar as diferenças sociais e oferecer oportunidades iguais. $\mathrm{O}$ trabalho na forma de que trata a Lei ${ }^{\circ} 10.097 / 2000$ é adequado para permitir que o adolescente continue com seus estudos e deve ser apoiado pela sociedade (Entrevista, fevereiro 2018).

O Conselheiro Y se diz contrário a Lei ao declarar: "sou contra, pois entendo que criança e adolescente devem ter sua ocupação de tempo integral na escola, proporcionando a ele conhecimento para a garantia de um futuro melhor". A fala dos Conselheiros é um tanto quanto legalista, tendo em vista que, encontram a solução para a questão do trabalho infantil, somente na escola, destinando a elas esse espaço, chegando a querer vê-las ocupadas em tempo integral.

Ao se referir apenas à escola como dispositivo de ocupação, questionamos o papel da família. Não cabe somente a escola o dever de assegurar o desenvolvimento de crianças e adolescentes, a família também tem esse papel. É preciso compreender que a família tem que assumir a responsabilidade de zelar pela integridade física e mental de seus tutelados. A criança e o adolescente necessitam viver cada etapa da vida de forma harmoniosa e prazerosa.

Cabe ao CT legitimar os direitos preconizados pelo Estatuto da Criança e Adolescente com a comunidade e, por fim, zelar pela sua autonomia no exercício do seu papel fiscalizador. As leis não são meras letras mortas, o CT é quem dará a vida a elas. Destarte, efetivar na prática a garantia dos direitos.

Vinte e nove anos se passaram desde a promulgação do ECA, uma lei criada para garantir a efetivação de direitos humanos da criança e adolescente e foi um marco na história do país, onde crianças e adolescentes eram estigmatizados pela sua condição social, permeados pela criminalização da pobreza. Atualmente o ECA é questionado pela comunidade, e isso se dá pelo fato das distorções que são propagadas. Os Conselheiros Tutelares tem contato direto com a comunidade, e conhecem de perto as dificuldades e desafios para conscientizá-la dos benefícios do ECA. Para o Conselheiro X,

A efetividade dos direitos da criança e adolescente depende também da consciência da comunidade. O ECA garante essa proteção e regula os órgãos envolvidos nessa função. Mas acredito que a comunidade ainda não conhece bem o Estatuto, pois muitos questionam alguns direitos garantidos às crianças e adolescentes, como por exemplo, o trabalho infantil. Como falta conhecimento é comum que em alguns casos que trabalhamos haja resistência da família em acatar e aceitar as soluções. Mas encontramos apoio dos que conhecem o ECA e as funções do Conselho Tutelar (Entrevista, fevereiro 2018).

\footnotetext{
${ }^{1} \mathrm{~A}$ criança e o adolescente têm direito à liberdade, ao respeito e à dignidade como pessoas humanas em processo de desenvolvimento e como sujeitos de direitos civis, humanos e sociais garantidos na Constituição e nas leis (ECA Online, 2018).
} 
Observa-se na fala do Conselheiro X que a comunidade questiona alguns direitos garantidos ao público infanto-juvenil, por falta de conhecimento ou entendimento, como diz o Conselheiro Y, que "a maioria das pessoas, entendem como o estatuto foi feito para dar "ousadia" às crianças e adolescentes; uma brecha para que eles façam o que quiser”. Nesse sentido, faz-se necessário a divulgação do ECA, como relata o Conselheiro W,

As varas da Infância, as promotorias da Infância e Juventude de todas as comarcas do Brasil precisam urgentemente divulgar o ECA e os Conselhos Tutelares, porque sabemos que muitos professores, delegados, escrivães, educadores sociais, não usam ou não conhece o ECA (Entrevista, fevereiro 2018).

Percebe-se através da fala do Conselheiro W, que mesmo o ECA completando no ano de 2019, vinte e nove anos de promulgação, ainda não conseguimos fazer com que a população reconheça a sua legalidade e, para ele, isso se deve a falta de campanhas de conscientização e mobilização da comunidade como um todo.

No próximo tópico, apresentaremos as ações desenvolvidas pelas Secretarias de Desenvolvimento Social e Educação, com o objetivo de erradicar o Trabalho infantil e garantir o acesso da criança e adolescente a uma educação de qualidade.

\section{Ações das Secretarias de Desenvolvimento Social e Secretaria de Educação para Erradicação do Trabalho Infantil}

Um dos mecanismos de enfrentamento ao trabalho infantil é o Programa de Erradicação do Trabalho Infantil (PETI), que teve início em 1996, como ação do governo federal, apoiado pela Organização Internacional do Trabalho (OIT), coordenado pela Secretaria de Assistência Social, e vinculado ao Ministério da Previdência Social e Assistência Social, a fim de combater o trabalho executado por crianças em carvoarias em Três Lagoas (MS). O objetivo era retirar crianças e adolescentes com idades entre 7 a 14 anos, das atividades consideradas as piores formas de trabalho infantil. Com o bom nível de desempenho do programa, sua cobertura foi ampliada, para os estados de Rondônia, Pernambuco, Sergipe e Bahia, posteriormente, para todo o país através da implementação do Sistema Único de Assistência Social (SUAS).

O PETI tinha como foco central as famílias que possuíam uma renda per capita de pelo menos 1/2 salário mínimo, e a realização de atividades socioeducacionais, além da geração de trabalho e renda, a fim de melhorar a qualidade e condições de vida das famílias. Segundo Souza (2016),

O alcance do programa era garantir o acesso e a permanência de crianças e adolescentes na escola, a oferta de atividades de contraturno por meio da jornada ampliada, a concessão de benefício mensal; orientação às famílias e a promoção de cursos e projetos de qualificação profissional. De acordo com os objetivos centrais do PETI, a 
permanência do aluno na escola era umas condicionalidades para a manutenção da criança ou do adolescente no programa, considerando como frequência mínima o índice de $85 \%$ (SOUZA, 2016, p.180).

As famílias que tinham crianças e adolescentes em situação de trabalho infantil, recebiam a quantia de $\mathrm{R} \$ 40,00$ (quarenta) reais por sujeito, caso fosse da zona urbana, e as famílias da zona rural recebiam $\mathrm{R} \$ 25,00$ (vinte e cinco) reais, valores repassados independente da quantidade de crianças e adolescentes por família.

Em 2005, através da Portaria 666, o Programa PETI foi integrado ao Programa Bolsa Família, ampliando a idade para inserção de crianças e adolescentes com a média de idade entre 0 a 15 anos. As ações da assistência social não se realizam de forma isolada, mas se articulam para a formação de uma rede de proteção social (BRASIL, 2014).

Em 2013, deu-se início as discussões sobre o Redesenho do PETI. O novo modelo de Programa visava acelerar as ações de prevenção e erradicação do trabalho infantil, bem como, a proteção do adolescente trabalhador, até o Redesenho do PETI. As principais ações eram,

Concessão de bolsa-criança cidadã para cada criança incluída na jornada escolar ampliada; II - atendimento de criança e adolescente em jornada escolar ampliada; III geração de ocupações produtivas para as famílias com crianças e adolescentes no PETI; IV - fiscalização do trabalho infantil; e V - mapeamento dos focos de trabalho infantil por município (RODRIGUES, 2015, p. 120).

O Redesenho do PETI consistiu na realização de ações estratégicas voltadas ao enfrentamento das novas configurações do trabalho infantil no Brasil e no fortalecimento do Programa em compasso com os avanços da cobertura e da qualificação da rede de proteção social do SUAS. Ele se destina a potencializar os serviços socioassistenciais existentes, bem como a articular ações com outras políticas públicas, o que favorece a criação de uma agenda intersetorial de erradicação do trabalho infantil.

Após a apresentação da configuração do PETI em âmbito nacional, visando conhecer o Programa, buscamos estudar a realidade do PETI no município de Itapetinga e, para isso, realizamos uma coleta de dados através da entrevista semiestruturada com o coordenador do Programa, o qual assumiu o cargo no mês de novembro de 2017.

O Programa está vinculado a Secretaria de Desenvolvimento Social, através da Proteção Social Especial, que está dividida em média e alta complexidade. A média complexidade oferta atendimentos socioassistenciais às famílias e sujeitos que tiveram os direitos ameaçados ou violados, que embora não tenham perdido o vínculo com seus familiares, precisam de acompanhamento especializado; já a alta complexidade tem como público alvo, o sujeito que de alguma forma, necessita ser retirado do convívio familiar e ou comunitário como medida protetiva.

A entrevista teve como objetivo conhecer a forma de atuação do Programa no município, bem como as ações estratégicas utilizadas no combate ao trabalho infantil. Para tanto, além da entrevista 
semiestruturada, utilizamos a gravação de áudio.

Já de início, buscamos saber do Coordenador do programa se existe algum banco de dados, onde tem o registro de crianças e adolescentes em situação de trabalho infantil no município e o entrevistado respondeu que,

O PETI não possui um banco de dados específico, existe na realidade o Sistema de Monitoramento do PETI - SIMPETI, onde as ações estratégicas do Programa são relatadas de forma resumida. As informações sobre incidência de Trabalho Infantil são fornecidas através do Relatório Mensal de Atendimento - RMA do CREAS e dos CRAS, do Sistema de Informação do Serviço de Convivência - SISC (CRAS) e do CadÚnico (COORDENADOR DO PETI, Entrevista, março 2018).

No PETI, não foi possível ter acesso a cadastro ou documentos que indicassem números e percentuais de crianças e adolescentes em situação de trabalho infantil, nos últimos dois anos no município. Entretanto, o Coordenador disponibilizou um Diagnóstico Intersetorial Municipal, confeccionado pelo Instituto Brasileiro de Geografia e Estatísticas (IBGE) - Censo (2010), que na época apontava um alto índice de crianças e adolescentes executando atividades trabalhistas no município.

Segundo o Censo (2010), a cidade de Itapetinga, em 2010, possuía uma população total de 68.273 mil habitantes, naquele momento havia 436 crianças e adolescentes, com idades entre dez e quinze anos ocupados. Outro dado que chama atenção, é a quantidade de vítimas executando tarefas domésticas, foram 120 crianças e adolescentes com idade entre 10 e 17 anos. O município contava com quatro Centros de Referência de Assistência Social (CRAS), um Centro de Referência Especializado de Assistência Social (CREAS) e uma Unidade de Atendimento ao Adolescente em conflito com a Lei (RECOMEÇAR).

Quase dez anos se passaram, o município cresceu e segundo o Censo (2018), a população está estimada em 75. 470 mil habitantes (IBGE, 2018), contudo, os órgãos, as instituições, os programas, que compõem o SGD, não tem um diagnóstico atualizado da situação de trabalho infantil no munícipio.

Para que ações de enfrentamento ao trabalho infantil sejam implementadas pelos municípios, é necessário um banco de dados, com informações relevantes que possam aperfeiçoar a forma de atendimento a criança e adolescente. Nesse sentido, é de fundamental importância que os programas estejam funcionando de forma conectada, para que as ações planejadas possam resultar na garantia de direitos humanos de crianças e adolescentes. Ao relatar as denúncias que chegam ao PETI, o Coordenador do Programa destacou que,

Ao receber alguma denúncia de Trabalho Infantil, o Coordenador do PETI encaminha a demanda para o Conselho Tutelar e CREAS, este último fará a busca ativa e constatando a veracidade da denúncia acompanhará a família e a criança ou adolescente através do PAEFI e encaminhará para o Serviço de Convivência nos CRAS (COORDENADOR DO PETI, Entrevista, março 2018).

Observa-se que na fala do Coordenador do PETI, ao receber denúncias de trabalho infantil, a demanda é encaminhada para o Conselho Tutelar, embora não esteja especificado o motivo de tal 
encaminhamento, é importante salientar que o CT não é Órgão de execução de medidas, pelo contrário, é através dele que são realizados os encaminhamentos de atendimentos necessários para promover direitos, ou seja, as medidas protetivas aplicadas. Por isso, é preciso que a rede de proteção a criança e ao adolescente participe de formação continuada, visando conhecer a funcionalidade de cada Órgão ou programa que faz parte da rede de proteção.

O PETI, até o ano de 2013, concentrava seus esforços nas ações socioeducativas, sendo estas ações supletivas ao ensino básico e se relacionam com o desenvolvimento da comunicação, sociabilidade, trocas culturais, atividades lúdicas, atividades artísticas, desportivas e/ou de aprendizagem. O que se pretendia era a ampliação do universo informacional, artístico e cultural das crianças e adolescentes; e ainda estimular o desenvolvimento de habilidades, talentos e principalmente propor a formação cidadã destes (BRASIL, 2010). No entanto houve várias mudanças deste a sua criação. Segundo o Coordenador do PETI,

O PETI funcionava como jornada ampliada, no contra turno escolar as crianças e adolescentes se reuniam para realizar diversas atividades e oficinas, o que hoje é função dos Serviços de Convivência. Em 2013, o PETI sofreu um redesenho deixando de ser jornada ampliada para atuar através de Ações Estratégicas do PETI de forma intersetorial e passou a denominar-se AEPETI. Tais ações estão respaldadas em cinco eixos de atuação: Informação e mobilização; Identificação; Proteção; Defesa e Responsabilização; e Monitoramento (COORDENADOR DO PETI, Entrevista, março 2018).

Com o Redesenho, o PETI passa a funcionar com ações estratégicas destinadas ao avanço e qualificação da rede de atendimento. Tivemos acesso ao relatório de atividades desenvolvidas pelo PETI e no ano de 2017 foram doze eventos que teve como tema: o trabalho infantil de crianças e adolescente, sendo onze de formação e apenas um de mobilização. No mês de setembro de 2017, houve uma mobilização realizada na Central de Abastecimento $^{2}$ com o objetivo de conscientizar os comerciantes e consumidores de que a contratação ou compra de produtos na mão de crianças e adolescentes em feiras livres (carregador e vendedor) não contribui para o desenvolvimento da família da criança.

Para a coordenação do PETI,

O ano de 2017 foi marcado por grandes desafios em todos os setores da Prefeitura Municipal de Itapetinga, inclusive o PETI que estava completamente desarticulado, com ações isoladas e sem repercussão alguma. O grande desafio está sendo articular novamente e promover, junto à comunidade itapetinguense, ações mais efetivas no combate ao trabalho infantil e adolescente (COORDENADOR DO PETI, Entrevista, março 2018).

Percebe-se através da fala do Coordenador do PETI, que no ano de 2017 houve dificuldades para que o Programa articulasse ações de impacto que viessem a conscientizar a comunidade local, sobre os malefícios causados pelo trabalho infantil. O enfrentamento ao trabalho infantil de forma alguma deve

${ }^{2}$ Espaço onde funciona a feira livre do Município de Itapetinga-Bahia. 
ser uma ação isolada do PETI, pois trata-se de um esforço conjunto dos diversos atores da promoção e garantia dos direitos da criança e adolescente.

Nesta perspectiva, a Secretaria Municipal de Educação de Itapetinga, no ano de 2017, implantou no município o Programa de Educação Contra a Exploração do Trabalho da Criança e do Adolescente (PETECA), denominado de MOLECADA.

O Programa de Educação Contra a Exploração do Trabalho da Criança e do Adolescente nasceu em 2008, no Estado do Ceará, desenvolvido pelo Ministério Público do Trabalho, em parceria com as Secretarias Estadual e Municipais de Educação, e os demais Órgãos e entidades do SGD. Este programa desenvolve um conjunto de ações a fim de conscientizar e sensibilizar a comunidade escolar, bem como a sociedade em geral sobre os direitos da criança e do adolescente, tendo como ponto central a erradicação do trabalho infantil e profissionalização do adolescente.

Em Itapetinga, o Programa MOLECADA conta com um coordenador ligado a Secretaria de Educação, e agentes públicos da Secretaria de Desenvolvimentos Social, Conselho Tutelar e outros, não sendo um grupo fixo, o que segundo o entrevistado,

Para uma melhor atuação é necessário que o Grupo de Trabalho seja fixo, o que não ocorreu, pelo fato de serem agentes públicos sujeitos a repentinas mudanças, como exemplo, ocorreu nesse período a mudança da Secretaria de Desenvolvimento Social, consequentemente, os representantes do Grupo de Trabalho também foram mudados, necessitando assim, formar os novos integrantes para atuarem no programa (COORDENADOR DO PETECA, Entrevista, março 2018).

As mudanças nas equipes que atuam na defesa dos direitos da criança e do adolescente, nos municípios tem se tornado corriqueiras, tendo em vista, que a maioria dos gestores contratam pessoas para trabalhar no setor de educação e social, correndo o risco de ter na equipe indivíduos que nunca tiveram compromisso com a causa, mas que por conta da crescente falta de emprego, aceitam trabalhar na área, visando à remuneração.

O programa PETECA/MOLECADA chega a Itapetinga como um programa inovador, um marco na história da Secretaria de Educação. Antes os programas relacionados ao enfrentamento ao trabalho Infantil eram sempre alocados na Secretaria de Desenvolvimento Social e com ações isoladas. O PETECA/MOLECADA trouxe essa mudança, passando a ser um dos principais programas de conscientização e mobilização. O Coordenador do ao falar sobre a parceria cita que,

[...] o Conselho Tutelar que é parceiro do PETECA/MOLECADA tinha dados de uma pesquisa realizada em uma feira da cidade, e já tinha constatado a existência de trabalho infantil. Fizemos uma pesquisa no âmbito escolar e conseguimos potencializar essa informação, fazendo um levantamento numérico bem maior e um mapeamento dos bairros onde ocorre maior índice de trabalho infantil, ficando assim mais fácil as ações na busca ativa e constatação direta das ocorrências (COORDENADOR DO PETECA, Entrevista, março 2018). 
A partir dos dados apresentados pelo Conselho Tutelar, a equipe do Programa PETECA/MOLECADA, percebendo a necessidade de um trabalho informativo e de conscientização sobre trabalho infantil e adolescente trabalhador aprendiz, iniciou uma jornada de palestras nas escolas municipais, onde foi disponibilizado aos gestores escolares um questionário, para ser entregue e respondido pelos alunos, visando diagnosticar o quadro de crianças e adolescentes estudantes da rede pública municipal, que já executou ou executa alguma atividade trabalhista.

A seguir apresentamos a Tabela 1, com o quadro de alunos que responderam ao questionário disponibilizado nas escolas públicas municipais.

TABELA 1 - Quadro de alunos que participaram da pesquisa

\begin{tabular}{|c|c|c|c|c|c|c|c|c|c|}
\hline \multicolumn{3}{|c|}{$\begin{array}{l}\text { TOTAL DE } \\
\text { ENTREVISTADOS }\end{array}$} & ALUN & & \multicolumn{3}{|c|}{$\begin{array}{l}\text { TOTAL DE } \\
\text { TRABALHAM }\end{array}$} & ALUNOS & QUE \\
\hline \multicolumn{5}{|c|}{441} & \multicolumn{5}{|c|}{800} \\
\hline \multicolumn{10}{|c|}{ MÉDIA DE IDADE } \\
\hline 9 & 10 & 11 & 12 & & 13 & 14 & 15 & 16 & 17 \\
\hline ANOS & ANOS & ANOS & ANOS & & NOS & ANOS & ANOS & ANOS & ANOS \\
\hline 77 & 87 & 102 & 149 & & 136 & 115 & 80 & 36 & 18 \\
\hline
\end{tabular}

Fonte: Elaborada pelo autor da pesquisa com base em dados Secretaria de Educação (2017)

Os dados apresentados na Tabela 1 são referentes ao diagnóstico realizado pelo Programa no mês de agosto de 2017, em 16 escolas públicas. Responderam ao questionário 4.421 alunos, sendo que 800 declararam exercer algum tipo de atividade considerada trabalho infantil. O diagnóstico foi feito com alunos de 9 (nove) a 17 (dezessete) anos. A tabela faz a separação dos alunos que trabalham por idade, revelando um grande número de crianças, e somando as crianças de nove a onze anos, obtivemos 266 crianças que se auto declararam trabalhadora, já os adolescentes somaram 534.

Observa-se que os dados apresentados pelo Programa revelam um problema grave de violação de direitos humanos de crianças e adolescentes, que precisa ser levado em consideração. É importante que esse diagnóstico seja socializado com o SGD e com a sociedade civil. A partir daí, deve ser criado estratégias de enfrentamento a exploração da mão de obra infantil.

Diferente do PETI, o Programa PETECA/MOLECADA não tem um incentivo financeiro para as famílias que possuem crianças em situação de trabalho infantil. O Coordenador do programa disse 
que;

[...] o PETECA/MOLECADA busca parceiros para esse fim, que é absorver o adolescente legalmente para o mercado de trabalho, onde os adolescentes que tem a partir de 14 anos de idade, já podem ter a carteira assinada como Aprendiz, o que é totalmente legal, desde que não seja trabalho insalubre, não ultrapasse 6 horas diárias e não seja noturno (COORDENADOR DO PETECA, Entrevista, março 2018).

No que diz respeito à formação, o Programa tem feito um trabalho de formação com seus coordenadores. Segundo o Coordenador,

[...] ocorreu uma formação na Procuradoria Geral da República na cidade de Salvador, onde foi formados os coordenadores municipais, para que formassem suas equipes nos seus respectivos municípios e assim, multiplicar o conhecimento e aumentar a difusão do programa (COORDENADOR DO PETECA, Entrevista, março 2018).

Verifica-se que o Programa PETECA/MOLECADA passa a ser um dos principais instrumentos de conscientização da comunidade itapetinguense, um elo entre educação e social no combate ao trabalho infantil e a garantia de direitos individuais inerentes ao adolescente trabalhador aprendiz.

\section{Considerações Finais}

O Brasil assumiu junto a Organização Internacional do Trabalho - OIT, o compromisso de erradicar todas as formas de trabalho infantil até o ano de 2020, contudo, a partir deste estudo percebese que estamos longe de alcançar tal meta, já que na primeira missão que era erradicar as piores formas de trabalho infantil, o país não conseguiu alcançar esse objetivo (OIT-2006).

Portanto, a proposta deste estudo foi abordar a questão do trabalho infantil, no município de Itapetinga-Bahia, com o intuito de conhecer as ações e estratégias utilizadas pelo poder público para erradicação desse fenômeno. No CT, analisamos as entrevistas com os Conselheiros Tutelares. Nota-se a importância do CT dentro do SGD, no combate ao trabalho infantil. Já que o CT recebe denúncias de violações dos direitos da criança e adolescente, cabe ao órgão imediatamente a aplicação medidas que devem ou deveriam restabelecer o direito violado, entretanto, ao analisar as entrevistas, percebe-se que muitas vezes essas medidas não são empregadas de forma correta. Há divergências nos atendimentos e encaminhamentos feitos pelos Conselheiros, o que pode colocar em risco os direitos individuais dos sujeitos. 
Em relação ao PETI, por não dispor de um banco de dados quantitativo de crianças e adolescentes em situação de trabalho precoce, foi disponibilizado para análise, um Diagnóstico Intersetorial do Município, organizado pela OIT em parceria com a Secretaria de Avaliação e Gestão de Informação (IBGE, Censo 2010). Esse documento traz informações importantes sobre a situação da criança e adolescente no município de Itapetinga. No entanto, de forma desatualizada, uma vez que os dados são referentes ao ano de 2010. Essa falta de atualização de dados referentes a crianças e adolescentes em situação de trabalho infantil, colabora para que as ações e estratégias do Programa não alcancem seus objetivos.

O PETECA, alocado na Secretaria de Educação, mostra-se como um importante instrumento na luta contra o trabalho infantil no município. Os dados coletados nos mostram que no ano de 2017 foi feito um trabalho importante, em que a equipe do Programa levou palestras e formação nos espaços educacionais, a fim de educar a população local para identificar os casos de trabalho infantil, bem como, os efeitos nocivos das atividades impostas às crianças e adolescentes. Foi feito diagnóstico em 16 (dezesseis) escolas da rede municipal de ensino, no qual foi constatado um grande número de alunos, que declaram já ter ou ainda estarem vivendo no contexto de trabalho infantil.

A análise dos dados conduziu-nos a um ponto que é da maior relevância quando se leva em conta as interpretações que se fazem a respeito das ações e estratégias de combate ao trabalho infantil. Nota-se que os órgãos e programas que visam combater o trabalho infantil no município de Itapetinga não têm demonstrado parceria no momento de agir, para retirar crianças, adolescentes e suas famílias do contexto de vulnerabilidade social e, consequentemente, reduzir o quantitativo de crianças e adolescentes que tem entrado precocemente no mercado de trabalho.

O fato é que os Órgãos, programas, instituições que tem como missão garantir os direitos humanos de crianças e adolescentes, tem trabalhado sem uma organização prévia, muito embora, cada um tem tentado cumprir o seu papel, porém de forma desarticulada, contribuindo para a perpetuação da violação de direitos humanos de crianças e adolescentes. 


\section{Referências}

ALBERTO, M. de F. P. A dimensão subjetiva do trabalho precoce de meninos e meninas em condição de rua em João Pessoa - Pb. Tese de Doutorado. Universidade Federal de Pernambuco, Recife, 2002.

BRASIL. Lei no 8.069, de 13 de julho de 1990. Estatuto da Criança e do Adolescente. Brasília, 1990.

BRASIL. Constituição (1988). Constituição da República Federativa do Brasil: promulgada em 5 de outubro de 1988. Contêm as emendas constitucionais posteriores. Brasília, DF: Senado, 1988.

BRASIL. Ministério do Desenvolvimento Social e Combate à Fome. Orientações técnicas sobre o serviço de Convivência e Fortalecimento de Vínculos para crianças e adolescentes de 06 a 15 anos. Brasília, 2010.

IBGE. Diretoria de Pesquisas, Coordenação de População e Indicadores Sociais, Estimativas da população residente 2018. Itapetinga, com data de referência $1^{\circ}$ de julho de 2017 . Disponível em https://cidades.ibge.gov.br/brasil/ba/itapetinga/panorama. Acessado em 01 de abril de 2019.

LIBERATI, Wilson Donizeti; CYRINO, Públio Caio Bessa. Conselhos e Fundos no Estatuto da Criança e do Adolescente. São Paulo: Malheiros, 1993

OIT (ORGANIZAÇÃO INTERNACIONAL DO TRABALHO). Trabalho Invisível? Só depende de você?. Brasília: OIT, 2003, FOLDER.

ONU (ORGANIZAÇÃO DAS NAÇÕES UNIDAS). Declaração dos Direitos da Criança. Comitê Social Humanitário e Cultural da Assembleia Geral, Genebra, jul. 1960.

RODRIGUES, M. R. G. O Combate ao Trabalho Infantil no Estado do Pará: O Redesenho do Programa de Erradicação do Trabalho Infantil (PETI) e a sua Efetividade. 1ed.Belém: CUP, 2015.

SOUZA, Ismael Francisco de. O reordenamento do Programa de Erradicação do Trabalho Infantil (PETI): estratégias para concretização de políticas públicas socioassistenciais para crianças e adolescentes no Brasil. Santa Cruz do Sul, 2016. 